\title{
Impact of a common mutation of the LDL receptor gene, in French-Canadian patients with familial hypercholesterolemia, on means, variances and correlations among traits of lipid metabolism
}

Roy M, Sing CF, Betard C, Davignon J. Impact of a common mutation of the LDL receptor gene, in French-Canadian patients with familial hypercholesterolemia, on means, variances and correlations among traits of lipid metabolism

Clin Genet 1995: 47: 59-67. (C) Munksgaard, 1995

Structural and functional studies of the gene coding for the low density lipoprotein receptor in patients with familial hypercholesterolemia have uncovered over 180 mutant alleles of the gene. Although the classical familial hypercholesterolemia phenotype is well known, the range of phenotypic variability in lipid traits associated with particular mutations in familial hypercholesterolemia has not been extensively documented. We investigated the phenotypic distributions of plasma markers of lipid metabolism from a large sample of unrelated individuals who are heterozygous for a single mutation, $a>10 \mathrm{~kb}$ deletion in the low density lipoprotein receptor gene, and compared these distributions with those from a sample of healthy controls. Patients were pair-matched for sex and age with healthy individuals selected from a previously studied French-Canadian population from the same region. We examined the level and variation of seven lipid traits, the correlations between the traits, and the amount of overlap of the sample distributions for each trait. The low density lipoprotein receptor defect was found to affect the levels and variability of traits, and correlations between traits. There was some overlap of the distributions of lipid traits including that for low density lipoprotein cholesterol, which is a cardinal feature of familial hypercholesterolemia. The low density lipoprotein receptor gene has a sex-specific pleiotropic effect and should be considered as a variability gene as well as a level gene. The extensive dynamic changes observed in the relationships between lipid traits testify to the biological complexity of genome type-environment interactions.

\section{Madeleine Roy, Charles F. Sing', C. Betard ${ }^{2}$ and Jean Davignon}

Clinical Research Institute of Montreal, Hyperlipidemia and Atherosclerosis Research Group, Montreal, Quebec, Canada; 'Department of Human Genetics, University of Michigan, Ann Arbor, Michigan, USA and ${ }^{2}$ MMAGE Project Research Center of Côte des Neiges Hospital Montréal, Québec, Canada
Key words: biological complexity - FH - LDL-R gene - lipid traits - phenotypic expression Dr M. Roy, IRCM, 110 Pine Avenue West, Montreal, Quebec, Canada, H2W IR7

Received 11 May, revised version received 30 August, accepted for publication 19 October 1994
As much as $50 \%$ of the variability in total plasma cholesterol (T-CHOL) level among individuals in the general population is associated with genetic variation (Sing \& Boerwinkle 1987, Sing et al. 1992). Individual specific, familial and shared environmental influences attributable to diet, physical activity and smoking behavior, together with measurement errors, account for the remainder.
Allelic variation at many genetic loci has been put forward as an explanation for the genetic component of interindividual variation in each of the plasma measures of lipid metabolism (Sing \& Moll 1990). On the other hand, mutations in a few genes known to contribute to this metabolism are believed to be the cause of large phenotypic effects. For example, certain mutations in the gene coding 
for the low density lipoprotein receptor (LDL-R) have large effects on the plasma level of low density lipoprotein cholesterol (LDL-C) in patients with familial hypercholesterolemia $(\mathrm{FH})$ (Hobbs et al. 1990).

Studies of patients with homozygous $\mathrm{FH}$ have revealed considerable genetic heterogeneity: there may be as many as 183 different alleles of this gene (Hobbs et al. 1990). These defective alleles have been subdivided into five functional classes based on their effects on the LDL-R protein. The average LDL-C may exceed normal levels two- to threefold in heterozygotes and as much as five- to sixfold in individuals with two defective alleles. Persons having such high plasma cholesterol levels have greatly increased risk of developing premature coronary heart disease (CHD) (Goldstein \& Brown 1989).

Little is known about the range of phenotypic variation associated with any particular LDL-R mutation. Every person carrying the same defective allele for the gene coding for the LDL-R is not expected to have the same plasma lipid levels or the same risk of developing CHD. This is because variation at many genetic loci other than those within the region of the LDL-R gene, as well as environmental variation, also influence lipid metabolism. Studies to estimate the penetrance function, in FH patients, of specific LDL$\mathrm{R}$ mutations have not been feasible because of the lack of large enough groups of patients carrying the same mutation. This limitation does not apply to one LDL-R mutation with a high prevalence in the French-Canadian population because of a founder effect (Bétard et al. 1992). This mutation is defined by a $>10 \mathrm{~kb}$ deletion $(10 \mathrm{~kb}$ deletion) located in the 5 ' region of the gene. The deletion removes the promoter and the first exon and results in an unexpressed allele (Hobbs et al. 1987).

The first object of the research reported here was to characterize the phenotypic distributions (penetrance function) of plasma measures of lipid metabolism for a large sample of unrelated individuals who are heterozygous for the same $10 \mathrm{~kb}$ deletion in the LDL-R gene. The second object was to establish the proportion of individuals with this deletion whose measures of lipid metabolism fall within the range of variability defined by a sample of healthy individuals. This addressed the issue of whether hypercholesterolemia is a sensitive discriminator of individuals who carry the $10 \mathrm{~kb}$ deletion in French Canadians. We therefore measured the average plasma levels and the intra-genotypic variances and correlations of lipid traits for the $10 \mathrm{~kb}$ heterozygote sample and compared them with those of a sample of healthy subjects without the deletion, drawn from the same ethnic group.

\section{Methods}

Sampling procedure

Persons heterozygous for the $10 \mathrm{~kb}$ deletion were identified as described below through the lipid clinic at the Clinical Research Institute of Montreal. This clinic serves the Montreal metropolitan area and surrounding region within a $50 \mathrm{~km}$ radius in the Province of Quebec, Canada. The vast majority of patients attending this clinic are of French Canadian ancestry. In 1987, Hobbs et al. first described a $>10 \mathrm{~kb}$ deletion in the LDL-R gene in patients with a clinical diagnosis of $\mathrm{FH}$, drawn from the patient population of this clinic (Hobbs et al. 1987). Evidence showing this deletion to correspond with one haplotype defined by five LDLR RFLPs was reported by Bétard et al. (1992). Continued screening of all $\mathrm{FH}$ patients from this clinic confirmed that approximately $60 \%$ of French-Canadian $\mathrm{FH}$ patients carry this $10 \mathrm{~kb}$ deletion in the 5' end of the LDL-R gene.

For this study, we selected 74 French-Canadian men and 72 women with the deletion, who were unrelated to the $3 \mathrm{rd}$ degree and had a diagnosis of FH (10 kb-FH) based on an elevated LDL-C level, the presence of tendon xanthomas in the patient (or a first-degree relative) and a personal or family history of premature CHD. We used baseline, treatment-free, lipid determinations from the first visit of each patient in the sample. However, these baseline measurements were made over a number of years and changed in detail with time as new techniques of lipid measurement became available. It was therefore impossible to include complete lipid data on all the $10 \mathrm{~kb}-\mathrm{FH}$ individuals in the sample without seriously restricting the sample size. Among the 72 women in the $10 \mathrm{~kb}-\mathrm{FH}$ sample, 11 were identified through a family member attending the clinic. The same holds true for 16 of the 74 men who were studied. A small number of patients were receiving lipid-lowering drugs prior to their initial evaluation. Any such medication was withdrawn for a minimum of 1 month before baseline lipid level determination (none had been on probucol). Individuals who had undergone partial ileal by-pass surgery, pregnant women and patients manifesting the severe FH phenotype associated with the presence of two defective LDL$\mathrm{R}$ genes were excluded from the $10 \mathrm{~kb}-\mathrm{FH}$ study group. No-one was excluded on the basis of any other medical condition or medication.

A control group of healthy white-collar workers was selected to be sex and age-frequency matched (within 5 years) to members of the $10 \mathrm{~kb}-\mathrm{FH}$ 
sample. This sample, identified as the HQ sample from the name of the public utility where these individuals worked, was selected from a larger sample of HQ workers who had participated in a study of healthy individuals described in detail by Xhignesse et al. (1991). Participants in that study had been selected for their health status, specifically excluding pregnant women and those with known clinical manifestations of cardiovascular disease, hypertension, diabetes, thyroid dysfunction, renal or liver dysfunction, hyperlipidemia ( $a$ posteriori hyperlipidemia was not excluded) and any chronic disorder requiring medication, abnormal or missing baseline liver or kidney function tests, or elevated blood glucose or uric acid levels. For the present study, all French Canadians in this sample were screened for the $10 \mathrm{~kb}$ deletion and another, infrequent, $5 \mathrm{~kb}$ deletion, both detected by the same restriction enzyme digests ( $\mathrm{Ma}$ et al. 1989). Neither deletion was detected in any of these individuals.

\section{Laboratory methods}

After a 12 h fast, blood samples for lipid, lipoprotein and apolipoprotein determinations were obtained by peripheral venipuncture into tubes containing $1.5 \mathrm{mg} / \mathrm{ml}$ disodium ethylenediamine tetraacetic acid ( $\mathrm{Na}_{2}$ EDTA), and were centrifuged within $2 \mathrm{~h}$. Plasma lipoproteins were separated under standard conditions by a combination of ultracentrifugation and heparin-manganese precipitation of the apo B-containing lipoproteins in the $\mathrm{d}=1.006 \mathrm{~g} / \mathrm{l}$ infranatant, according to the Lipid Research Clinics Protocol (Lipid Research Clinics Program, 1974). Plasma and lipoprotein cholesterol and triglycerides (TG) were measured enzymatically on an automated analyzer (Technicon I before 1979, Abbott Bichromatic Analyzer 100, Abbott Laboratories, Pasadena, $\mathrm{Ca}$.). Technicon measurements were adjusted according to a regression equation established from multiple interassay measurements comparing the two methods. A strict quality control program was in effect in our laboratory and interassay variability was maintained at or below $5 \%$ while each method was used. Very low density lipoprotein-apolipoprotein B (VLDL-B) and low density lipoprotein-apolipoprotein B (LDL-B) were measured by electroimmunoassay (LussierCacan et al. 1985), using a commercial serum (Behringwerke, Marburg, West Germany) and a frozen serum pool as secondary standards. Routine biochemistry analyses including SMAC and liver function studies were also performed on blood drawn under the same fasting conditions. The presence or absence of the $10 \mathrm{~kb}$ (and $5 \mathrm{~kb}$ ) deletion was determined as described by Ma et al. (1989).

\section{Statistical methods}

The Statistical Analysis System, developed by the SAS Institute (SAS Institute Inc., 1989), was used. Since previous studies have shown that the frequency distributions for lipids, apolipoproteins and concomitants are sex-specific (Gordon et al. 1977, Lipid Research Clinics Program Epidemiology Committee 1979, Abbott et al. 1983, Wilson et al. 1983, Reilly et al 1990, Reilly et al. 1991, Sing \& Reilly 1993), data for women and men were analyzed separately. The level of statistical significance was taken as 0.05 .

The means and variances of concomitants and of lipid, lipoprotein and apolipoprotein traits were compared for differences between the $10 \mathrm{~kb}-\mathrm{FH}$ and HQ samples. When trait variances were found to be significantly different between the $10 \mathrm{~kb}-\mathrm{FH}$ and HQ samples, the degrees of freedom for the $t$-tests of means were computed according to the formula given by Dixon \& Massey (1969). An analysis of covariance was then carried out, separately for women and men, to estimate the contribution of the concomitants to lipid, lipoprotein and apolipoprotein variation, and to test the homogeneity of the regression equations between the $10 \mathrm{~kb}-\mathrm{FH}$ and HQ samples. Each lipid, lipoprotein and apolipoprotein trait was adjusted by the appropriate regression equation for variation in age, age squared, weight and height before comparing means, variances, and correlations between the 10 $\mathrm{kb}-\mathrm{FH}$ and HQ samples. When there was evidence for heterogeneity of regression between the $10 \mathrm{~kb}$ FH and HQ samples, separate adjustments were carried out for each sample. The distributions of adjusted data were plotted as $\mathrm{mmol} / \mathrm{l}$ or $\mathrm{mg} / \mathrm{dl}$ (VLDL-B and LDL-B).

\section{Results}

Table 1 shows that average age and weight of men and women in the $10 \mathrm{~kb}-\mathrm{FH}$ sample were not significantly different from those in the HQ sample. However, in both sexes, average height in the 10 $\mathrm{kb}-\mathrm{FH}$ sample was significantly lower than in the HQ sample, though without being significantly more variable within samples. In women, age is significantly more variable among members of the $10 \mathrm{~kb}-\mathrm{FH}$ sample than among members of the HQ sample. In both sexes, weight was significantly more variable within the $10 \mathrm{~kb}-\mathrm{FH}$ sample.

We removed the contribution of variation in age, age squared, weight and height to the variation in each of the lipid, lipoprotein and apolipoprotein traits. We found statistically significant heterogeneity between the $10 \mathrm{~kb}-\mathrm{FH}$ and HQ samples for the regression on these four concomitants for one 


\section{Roy et al.}

Table 1. Age, weight and height of $72 \mathrm{HQ}$ women and $74 \mathrm{HQ}$ men (controls) and equal numbers of $10 \mathrm{~kb}-\mathrm{FH}$ (patients)

\begin{tabular}{|c|c|c|c|c|c|c|c|c|}
\hline \multirow[b]{2}{*}{ Variable } & \multicolumn{3}{|c|}{$H Q$} & \multicolumn{3}{|c|}{$10 \mathrm{~kb}-\mathrm{FH}$} & \multicolumn{2}{|c|}{$p$-value } \\
\hline & $n$ & Mean & Variance & $n$ & Mean & Variance & $t$-test of means & F-test of variance \\
\hline \multicolumn{9}{|l|}{ WOMEN } \\
\hline Age $(y r)$ & 72 & 37.04 & 52.660 & 72 & 39.50 & 123.324 & 0.1184 & 0.0004 \\
\hline Weight (kg) & 72 & 58.43 & 48.744 & 72 & 58.23 & 112.852 & 0.8907 & 0.0005 \\
\hline Height (m) & 72 & 1.61 & 0.003 & 72 & 1.57 & 0.003 & 0.0002 & 0.7692 \\
\hline \multicolumn{9}{|l|}{ MEN } \\
\hline Age (yr) & 74 & 35.74 & 57.755 & 74 & 34.92 & 73.144 & 0.5364 & 0.3150 \\
\hline Weight (kg) & 74 & 74.05 & 78.742 & 74 & 73.33 & 149.359 & 0.6845 & 0.0069 \\
\hline Height (m) & 74 & 1.74 & 0.004 & 74 & 1.72 & 0.004 & 0.0170 & 0.5202 \\
\hline
\end{tabular}

or more of the lipid traits, for women and men considered separately. This justified separate adjustments for each sample for all traits.

Table 2 presents the means and variances of the adjusted data (unadjusted data not presented; adjusted data identified by prefix A). As expected, the variances of the lipid, lipoprotein and apolipoprotein traits were reduced after adjustment in each sample for both sexes, so that the adjustments increased the level of statistical significance for differences between the group means. The increase in statistical significance for the tests of the differences between the two groups suggests greater heterogeneity of the variances after removal of variation in concomitants. As we observed for the unadjusted high density lipoprotein cholesterol (HDL-C) data, the difference between the variance of AHDL-C for the $10 \mathrm{~kb}-\mathrm{FH}$ and HQ samples in men did not reach statistical significance. However, taking the means into account, the coefficients of variation were large and showed that the variability of the AT-CHOL and AHDL-C tended to be similar for the $10 \mathrm{~kb}-\mathrm{FH}$ and HQ samples of both sexes and that the variability of the ALDL-C and ALDL-B were smaller for the $10 \mathrm{~kb}-\mathrm{FH}$ samples.

Fig. 1 is a diagrammatic representation of the statistically significant (at the 0.01 level of probability) pairwise correlations between adjusted lipid, lipoprotein and apolipoprotein traits. As expected, there is a positive correlation between ATG and AVLDL-C and AVLDL-B in women and men in both samples; the same is true for ALDL-C and ALDL-B. AHDL-C and ATG are not correlated except for a weak negative correlation in the HQ women sample. In the female samples, there is a

Table 2. Plasma lipid, lipoprotein and apolipoprotein B concentration in HO (controls) and $10 \mathrm{~kb}$ - FH (patients) adjusted for age, age $\mathrm{e}^{2}$, weight and height

\begin{tabular}{|c|c|c|c|c|c|c|c|c|c|c|}
\hline \multirow[b]{2}{*}{ Trait $^{1}$} & \multicolumn{4}{|c|}{$\mathrm{HO}$} & \multicolumn{4}{|c|}{$10 \mathrm{~kb}-\mathrm{FH}$} & \multicolumn{2}{|c|}{$p$-value } \\
\hline & $n$ & Mean & Variance & $\begin{array}{c}\text { Coefficient of } \\
\text { variation } \%\end{array}$ & $n$ & Mean & Variance & $\begin{array}{c}\text { Coefficient of } \\
\text { variation \% }\end{array}$ & $\begin{array}{c}t \text {-test of } \\
\text { means }\end{array}$ & $\begin{array}{l}\text { F-test of } \\
\text { variance }\end{array}$ \\
\hline \multicolumn{11}{|l|}{ WOMEN } \\
\hline AT-CHOL $(\mathrm{mm} / \mathrm{l})$ & 72 & 4.75 & 0.495 & 14.87 & 72 & 9.95 & 2.146 & 14.77 & 0.0001 & 0.0001 \\
\hline ATG $(\mathrm{mm} / \mathrm{l})$ & 72 & 0.77 & 0.103 & 41.82 & 72 & 1.77 & 1.092 & 59.25 & 0.0001 & 0.0001 \\
\hline AHDL-C $(\mathrm{mm} / \mathrm{l})$ & 72 & 1.31 & 0.084 & 22.20 & 67 & 1.00 & 0.043 & 20.82 & 0.0001 & 0.0073 \\
\hline ALDL-C (mm/l) & 72 & 2.98 & 0.402 & 21.35 & 67 & 7.85 & 1.538 & 15.86 & 0.0001 & 0.0001 \\
\hline AVLDL-C $(\mathrm{mm} / \mathrm{l})$ & 72 & 0.45 & 0.036 & 42.31 & 67 & 0.97 & 0.268 & 53.57 & 0.0001 & 0.0001 \\
\hline ALDL-B (mg/dl) & 72 & 96.24 & 373.970 & 20.16 & 52 & 220.62 & 956.791 & 14.09 & 0.0001 & 0.0003 \\
\hline AVLDL-B $(m g / d)$ & 72 & 8.63 & 30.568 & 64.29 & 52 & 26.75 & 653.072 & 95.98 & 0.0001 & 0.0001 \\
\hline \multicolumn{11}{|l|}{ MEN } \\
\hline AT-CHOL. $(\mathrm{mm} /)$ & 74 & 4.81 & 0.720 & 17.70 & 74 & 9.56 & 1.640 & 13.45 & 0.0001 & 0.0006 \\
\hline ATG $(\mathrm{mm} / \mathrm{l})$ & 74 & 1.02 & 0.170 & 40.56 & 74 & 1.78 & 0.757 & 49.05 & 0.0001 & 0.0001 \\
\hline AHDL-C $(\mathrm{mm} / \mathrm{l})$ & 74 & 1.08 & 0.048 & 20.36 & 68 & 0.84 & 0.044 & 25.06 & 0.0001 & 0.7050 \\
\hline ALDL-C (mm/l) & 74 & 3.14 & 0.615 & 25.06 & 68 & 7.59 & 1.680 & 17.14 & 0.0001 & 0.0001 \\
\hline AVLDL-C $(\mathrm{mm} / \mathrm{l})$ & 74 & 0.59 & 0.046 & 36.77 & 68 & 1.16 & 0.557 & 64.58 & 0.0001 & 0.0001 \\
\hline ALDL-B (mg/dl) & 74 & 103.93 & 566.337 & 22.98 & 58 & 221.40 & 1367.048 & 16.77 & 0.0001 & 0.0004 \\
\hline AVLDL-B $(\mathrm{mg} / \mathrm{d})$ & 74 & 10.79 & 60.306 & 72.21 & 58 & 25.31 & 290.333 & 67.61 & 0.0001 & 0.0001 \\
\hline
\end{tabular}

'AT-CHOL, adjusted total cholesterol; ATG, adjusted triglycerides; AHDL-C, adjusted high density lipoprotein cholesterol; ALDL-C, adjusted low density lipoprotein cholesterol; AVLDL-C, adjusted very low density lipoprotein cholesterol; ALDL-B, adjusted apolipoprotein B of low density lipoprotein; AVLDL-B, adjusted apolipoprotein $B$ of very low density lipoprotein, $\mathrm{mm} / \mathrm{l}$, millimole per liter; $\mathrm{mg} / \mathrm{dl}$, milligram per deciliter. 


\section{WOMEN}

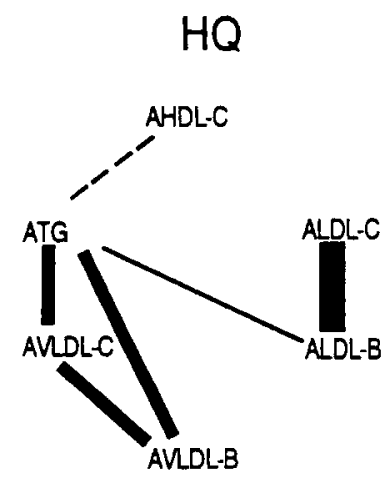

10KB-FH

AHDL-C
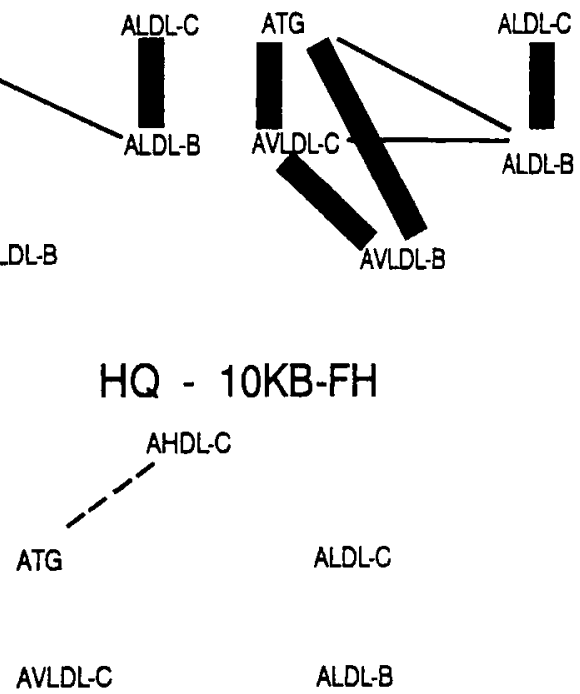

AVLDL-B
MEN

$\mathrm{HQ} \quad$ 1OKB-FH

AHDL-C

AHDL-C
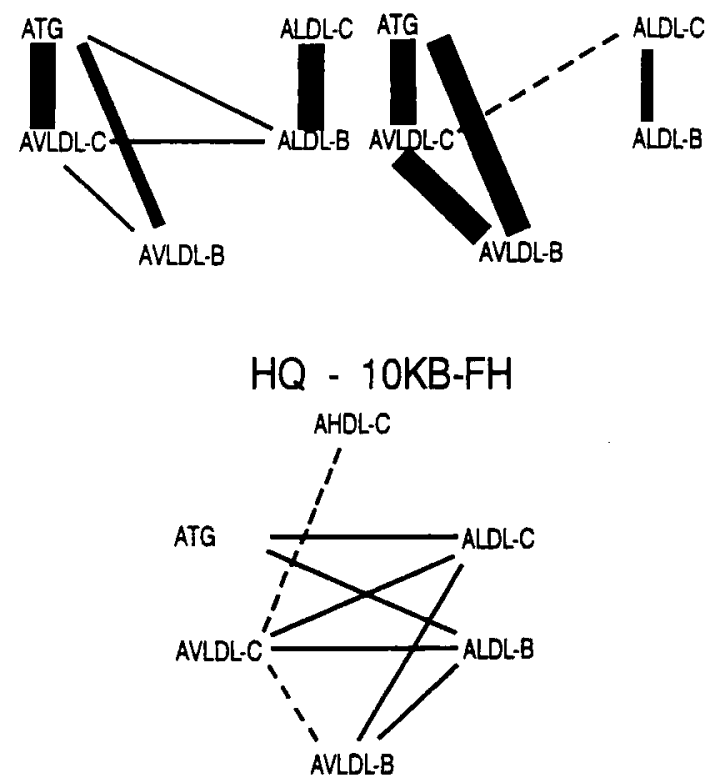

Fig. 1. Statistically significant Pearson product correlations where - - represents a correlation between -0.5 and $-0.3,-$ represents a correlation between 0.3 and 0.5, represents a correlation between 0.5 and 0.7 and - represents a correlation between 0.7 and 1.0 .

weak positive correlation between ALDL-B and ATG, whereas ALDL-B and AVLDL-C are weakly correlated in the $10 \mathrm{~kb}-\mathrm{FH}$ sample only. In men, the HQ sample shows correlation between ALDL-B and ATG and between ALDL-B and AVLDL-C which are absent in the $10 \mathrm{~kb}-\mathrm{FH}$ sample, and there is a weak negative correlation between ALDL-C and AVLDL-C in the $10 \mathrm{~kb}-\mathrm{FH}$ sample which is absent in the HQ sample.

Contrasting the strength of the correlations by computing their differences (HQ minus $10 \mathrm{~kb}-\mathrm{FH}$ ) shows that in women, only the negative difference between the AHDL-C - ATG correlations is statistically significant (at the 0.05 level of probability). For the men, the difference in strength of the correlations between lipid traits is significant for AHDL-C - AVLDL-C (weaker in HQ), ATG ALDL-C, ALDL-C - AVLDL-B and ALDL-B AVLDL-B (stronger in HQ), traits between which there is no significant correlation within each sample. The difference is also significant for correlations between ATG - ALDL-B and AVLDL-C ALDL-B that are weakly significant in the HQ but not in the $10 \mathrm{~kb}-\mathrm{FH}$ sample, between ALDL-C AVLDL-C that is weakly significant in the $10 \mathrm{~kb}-$
FH but not in the HQ sample and between AVLDL-C - AVLDL-B (weaker in HQ).

Again considering sexes separately, the frequency distributions of adjusted data are plotted in Fig. 2 to illustrate the observed dispersion of values and the extent of overlap of the $10 \mathrm{~kb}-\mathrm{FH}$ with the HQ sample. In women, there was only $1 \%, 0 \%$ and $2 \%$ overlap respectively for AT-CHOL, ALDL-C and ALDL-B. There was considerable overlap of the AHDL-C distributions, with lower values more frequent in the $10 \mathrm{~kb}-\mathrm{FH}$ sample although $3 \%$ of values in the HQ distribution were at or below the 20th percentile of the $10 \mathrm{~kb}-\mathrm{FH}$ distribution. For ATG, AVLDL-C and AVLDL-B, all values in the HQ sample fell within the range of values in the $10 \mathrm{~kb}-\mathrm{FH}$ sample. However, because of the greater skewness of the frequency distribution of the $10 \mathrm{~kb}-\mathrm{FH}$ sample, only $0 \%, 1 \%$ and $0 \%$ of the respective HQ values fell at or above the 80th percentile of the $10 \mathrm{~kb}-\mathrm{FH}$ distributions.

In men, the overlap for AT-CHOL, ALDL-C and ALDL-B was $1 \%, 1 \%$ and $9 \%$ respectively (confdence interval 0.0125 to 0.1599 for ALDL-B). Other observations followed those for women, with considerable overlap of the AHDL-C distri- 
Roy et al.

\section{WOMEN}

AT-CHOL

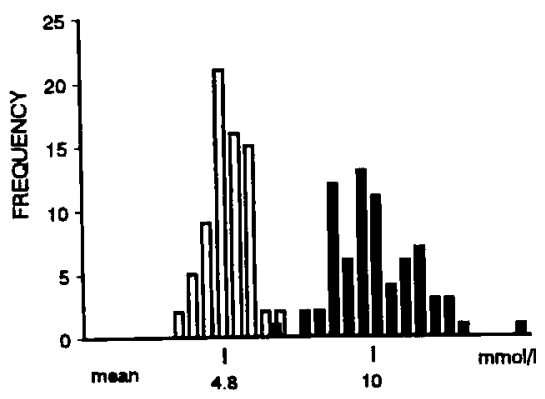

ALDL-C

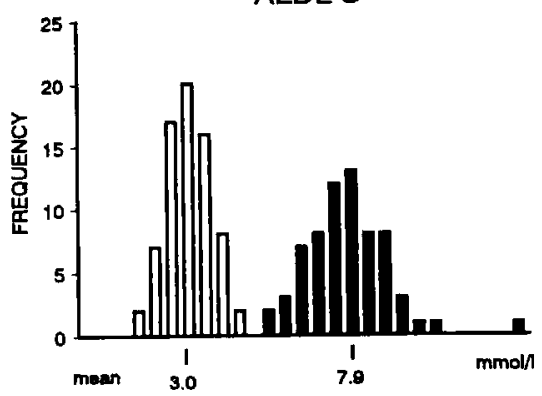

ALDL-B
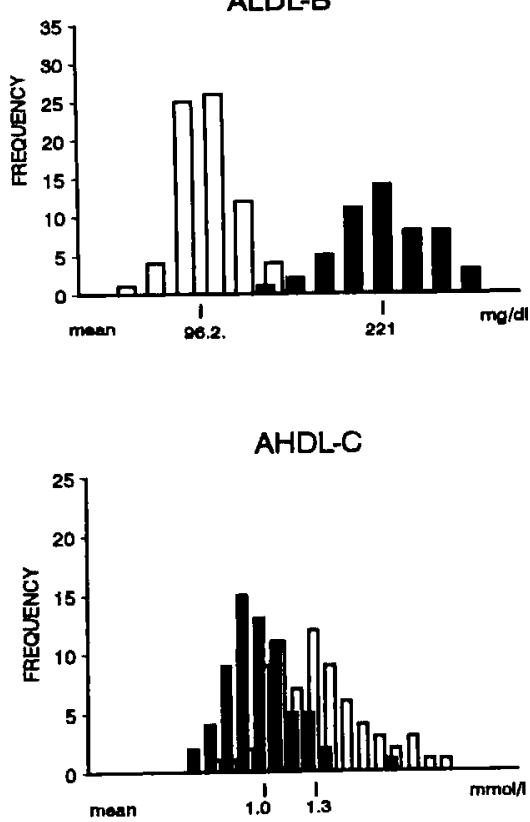

ATG

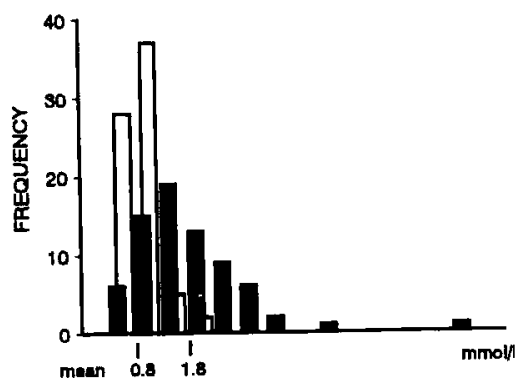

AVLDL-C
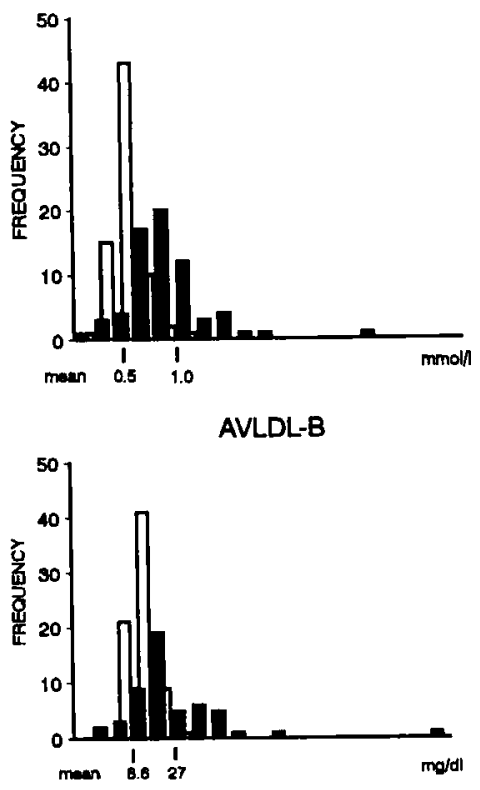

Fig. 2. Frequency distibution of adjusted data by sex where represents the $10 \mathrm{~kb}-\mathrm{FH}$ distribution and $\square$ represents the HQ distribution. butions, lower values being more frequent in the $10 \mathrm{~kb}-\mathrm{FH}$ sample, although $5 \%$ of values in the HQ distribution were at or below the 20th percentile of the $10 \mathrm{~kb}-\mathrm{FH}$ distribution. For ATG, AVLDL-C and AVLDL-B, all values observed in the HQ sample fell within the range of values observed in the $10 \mathrm{~kb}-\mathrm{FH}$ sample. Again because of the greater skewness of the frequency distribution of values in the $10 \mathrm{~kb}-\mathrm{FH}$ sample, only $4 \%, 0 \%$ and $0 \%$ of HQ values fell at or above the 80th percentile of the $10 \mathrm{~kb}-\mathrm{FH}$ distributions.

\section{Discussion}

The strong influence of mutations in the LDL-R gene on LDL-C and LDL-B levels is well known, but the extent of the variation in lipid, lipoprotein and apolipoprotein traits in $\mathrm{FH}$ patients and the 
associations between these traits have not been explored within groups of patients carrying the same mutation. Availability of DNA typing offers an unprecedented opportunity to study the penetrance function of identical mutations in the LDL-R gene in individuals diagnosed as having FH. The particular genetic makeup of the FrenchCanadian population enabled us to document the range of phenotypic variability, in $\mathrm{FH}$ patients, associated with a well-characterized mutation in the LDL-R gene, $a>10 \mathrm{~kb}$ deletion, which has a high prevalence in $\mathrm{FH}$ patients in this population.

In this study, the subjects chosen were unrelated to the 3rd degree, in order to minimize the selection bias pertaining to their common genetic background, thus providing a better estimate of the phenotypic variability among FH subjects heterozygous for this $10 \mathrm{~kb}$ deletion. The variability we observed underestimates the true variability of phenotypes among subjects with the $10 \mathrm{~kb}$ deletion genotype in the general population. Since most patients diagnosed as $\mathrm{FH}$ are referred to a specialized lipid clinic because of hyperlipidemia or heart disease, some carriers may not come to medical attention because of the presence of a milder phenotype. A small number of subjects with LDL-C levels in the normal range of variability, who are obligate heterozygotes for an LDL-R mutation and were identified through a family study because of a homozygous offspring, have been described in the literature (Nora et al. 1985, Hobbs et al. 1989, Uauy et al. 1991).

There is no published report of extensive population screening, using molecular methods for genotyping, to assess the prevalence of a specific mutation known to cause $\mathrm{FH}$ in a particular ethnic group and to determine its true phenotypic variability, i.e. penetrance function. Such a screening of the general population could also estimate the relative frequency of specific LDL-R mutations within the apparently healthy population at large.

Table 1 shows that despite successful matching for age and weight, average height was significantly lower in the $10 \mathrm{~kb}-\mathrm{FH}$ samples, which raises the possibility that the disturbance in lipid metabolism may have interfered in subtle ways with the growth process of the $\mathrm{FH}$ patients (Miettinen \& Aro 1972). The sampling procedure for obtaining the healthy group of individuals from which our HQ sample was drawn accounts for differences in variability of age and weight between the samples.

The 2- to 3-fold increase in the mean levels of ALDL-C and ALDL-B and the extent of variability for these traits (Table 2) are similar to previous reports of $\mathrm{FH}$ groups carrying undefined mutations (Thompson et al. 1989, Hobbs et al. 1987). Since this $10 \mathrm{~kb}$ deletion results in an unex- pressed allele, these patients are functional hemizygotes (Hobbs et al. 1990). Their LDL-C level is likely to be influenced strongly by the LDL-R allele without the $10 \mathrm{~kb}$ deletion, and by other genetic and environmental factors specific to the individual.

The means of other lipid traits were also consistent with published values for $\mathrm{FH}$ patients. The ATG, AVLDL-C and AVLDL-B means of the HQ samples of both sexes are lower and AHDL-C means higher, reflecting the selection criteria of the healthy samples. HDL-C levels have been reported to be lower on average in $\mathrm{FH}$ individuals, whatever their age (Gagné et al. 1979) and in patients with coronary artery disease (Frohlich et al. 1989, Hill et al. 1991). Since many of the FH patients come to medical attention because of cardiac problems, this may constitute a selection bias which cannot be quantified.

The lipid and apolipoprotein trait variances are greater in the $10 \mathrm{~kb}-\mathrm{FH}$ than in the HQ samples, except for AHDL-C where the difference is significantly greater in the HQ women sample and not significantly different between the $\mathrm{HQ}$ men samples. The selection bias mentioned above may contribute to this finding. Thus, the variability observed in the $10 \mathrm{~kb}-\mathrm{FH}$ women and men samples is greater than that observed in the corresponding healthy samples. However, when the means of the samples are taken into account by computing the coefficient of variation, the variability of ALDL-C and ALDL-B levels proved to be smaller in the presence of the $10 \mathrm{~kb}$ deletion than in its absence, even though variability was curtailed by the exclusion of diseased and/or previously diagnosed hyperlipidemic individuals from the healthy samples. The coefficient of variation for AHDL-C levels shows that in fact the variability of this trait was similar in the $10 \mathrm{~kb}-\mathrm{FH}$ and HQ women.

The strong correlations between lipid traits observed in the healthy samples are present in the 10 $\mathrm{kb}-\mathrm{FH}$ samples, although their strength is altered in men. This is notably true of correlations between ALDL-C and ALDL-B, and between ATG and AVLDL-C and AVLDL-B, reflecting their close metabolic links. However, weaker correlations between traits of cholesterol and triglyceride metabolism are significantly more disrupted in $10 \mathrm{~kb}-\mathrm{FH}$ men, suggesting a sex-dependent disturbance of homeostasis extending beyond the obviously altered LDL-C metabolism in FH individuals.

Given the large variation in the levels of the traits in all samples, we observed overlap of the distributions of values between the HQ and $10 \mathrm{~kb}-\mathrm{FH}$ samples for most traits. Overlapping of AHDL-C levels with lower values found in the $10 \mathrm{~kb}-\mathrm{FH}$ samples is consistent with the literature on $\mathrm{FH}$ (Hill 
et al. 1991) and may in part be ascribed to a selection bias, i.e. the diseased $\mathrm{FH}$ individuals, with lower HDL-C levels, having a greater probability of coming to medical attention than the healthy ones of the same age. For the AT-CHOL distributions in both sexes and ALDL-C distributions in men only, there is overlap of the upper tail of the HQ distributions with the lower tail of the $10 \mathrm{~kb}-\mathrm{FH}$ distributions, illustrating the fact that these traits considered alone are not indicators of the presence of the $10 \mathrm{~kb}$ deletion. Overlapping of the ALDL-B distributions in both sexes suggests that high LDL-B values are common in a healthy population, particularly in men, and that they are less prevalent in women, at least before the menopause. A strong atherogenic potential has been ascribed to increased levels of apolipoprotein B (Teng et al. 1986). The healthy individuals who have values of ALDL-B within the range of the $10 \mathrm{~kb}-\mathrm{FH}$ distribution may be those who have a greater predisposition to CHD.

Variation in the LDL-R gene determines large phenotypic effects (Goldstein \& Brown 1989). The presence of this $10 \mathrm{~kb}$ deletion in the LDL-R gene has a major influence on one trait, LDL-C. Therefore, it is a "level" gene. But it is also a variability and a covariability gene, giving rise to dynamic changes in the variability and the relationships between traits belonging to the same metabolic pathway (Berg 1990). These observations argue that this $10 \mathrm{~kb}$ deletion in the LDL-R gene influences the phenotypic plasticity and coordinated metabolism of several lipid and lipoprotein traits. Inherent biological interactions whose function is to maintain homeostasis are altered between related traits of lipid metabolism, so that the pattern of associations among the traits in the $10 \mathrm{~kb}-\mathrm{FH}$ sample is different from that found in healthy individuals (Kozlowska et al. 1988, Reilly et al. 1994). Our study also shows that these alterations are sex-dependent.

Certain mutations may play a complex role in the coherence of the relationships between traits in the same metabolic pathway and in the adaptive system whose function is to maintain homeostasis (Sing \& Davignon 1993). Therefore, the concept that one gene influences a single trait should be broadened to include the study of genotype-dependent profiles of means, variances and correlations between metabolically related traits. This approach will better account for the phenotypic plasticity and the biological complexity of the relationships that we observe and will provide insights for modeling complicated gene effects.

Since the gene effect is context-dependent, this pattern is in turn influenced by the "genome type", or genetic background of the individual, and by exposure of the individual to the environment. Differences in the genetic background between affected individuals will lead to individual specific variation in phenotypic expression. Moreover, variation in the environmental context over time can be expected to induce dynamic changes in an extended network of intermediate traits as an adaptive response that is modulated by the genome type of the individual (Sing \& Reilly 1993, Zerba \& Sing 1993). The biochemical and physiological determinants of the phenotype are emergent properties of combinations of genes and environments ultimately specifying risk of disease (Sing et al. 1992, Sing \& Reilly 1993, Sing et al. 1993, Zerba \& Sing 1993).

In conclusion, we studied a major genetic defect, namely a mutation in the gene coding for the LDL-R resulting in an unexpressed allele, in order to estimate the impact of such a defect on phenotypic variation in traits of lipid metabolism. We compared the penetrance function describing individuals who are heterozygous for the same LDL$\mathrm{R}$ mutation and diagnosed as $\mathrm{FH}$, with that for a sample of healthy control individuals, from the same ethnic background, in whom the presence of this specific mutation has been excluded. This comparison has shown that, after adjustment for basic concomitants, the average levels and dispersions of traits, as well as the associations between particular pairs of these traits, are affected by this major monogenic defect. A coherent network of intermediate traits of lipid metabolism is profoundly disturbed by variation at a single locus. The alterations observed in the penetrance function of the gene are sex-dependent. This is important in comprehending the emergent properties of this network when it is disturbed by a major mutation. Furthermore, comparison of the distributions of adjusted LDL-C and LDL-B between the healthy control and $10 \mathrm{~kb}-\mathrm{FH}$ groups has shown overlap. The true penetrance function, with respect to lipid traits, which is associated with particular mutations in the LDL-R gene, will only be assessed by population screening in populations with known high prevalence of the mutations.

\section{Acknowledgements}

We thank the administration and employees at Hydro-Quebec, Montreal, who participated in a prior study from which our sample of healthy individuals was drawn. We are also grateful to Martha Haviland from the Department of Human Genetics, University of Michigan, Ann Arbor, Mich. who helped in the analyses of the data. This work was supported by grants from the Medical Research Council of Canada/CIBA Geigy Canada (Ul-0029), L'Institut de recherche en santé et en sécurité du travail (IRSST) du Québec, La Succession J.A. DeSève and Hydro-Québec.

\section{References}

Abbott RD, Garrison RJ, Wilson PWF, Epstein FH, Castelli 


\section{LDL-R gene: a level and variability gene}

WP, Feinleib M, Larue C. Joint distribution of lipoprotein cholesterol classes. Arteriosclerosis 1983: 3: 260-272.

Berg K. Level genes and variability genes in the etiology of hyperlipidemia and atherosclercsis. In: Berg K, Retterstøl N, Refsum S, eds. From phenotype to gene in common disorders. Copenhagen: Munksgaard A/S International Press, 1990: 77-91.

Bétard C, Kessling AM, Roy M, Chamberland A, Lussier-Cacan S, Davignon J. Molecular genetic evidence for a founder effect in familial hypercholesterolemia among French Canadians. Hum Genet 1992: 88: 529-536.

Dixon WJ, Massey FJ, Jr. Introduction to statistical analysis. New York: McGraw-Hill, 1969.

Frohlich JJ, Seccombe DW, Pritchard PH. The role of apoproteins in disorders of lipoprotein metabolism. Clin Biochem 1989: 22: $51-56$

Gagné C, Moorjani S, Brun D, Toussaint M, Lupien PJ. Relationship between plasma lipids, lipoproteins, clinical manifestations and ischaemic heart disease in men and women Atherosclerosis 1979: 34: 13-24.

Goldstein JL, Brown MS. Familial hypercholesterolemia. In: Scriver CR, Beaudet AL, Sly WS, Valle D, eds. The metabolic basis of inherited disease I. New York: McGraw-Hill, 1989: $1215-1250$

Gordon T, Castelli WP, Hjortland MC, Kannel WB, Dawber TR. Diabetes, blood lipids, and the role of obesity in coronary heart disease risk for women. Ann Intern Med 1977: 87: $393-397$

Hill JS, Hayden MR, Frohlich JJ, Pritchard PH. Genetic and environmental factors affecting the incidence of coronary artery disease in heterozygous familial hypercholesterolemia. Arteriosclerosis 1991: 11: 290-297.

Hobbs HH, Brown MS, Russel DW, et al. Deletion in the gene for the low-density lipoprotein receptor in a majority of French Canadians with familial hypercholesterolemia. N Engl J Med 1987: 317: 734-737.

Hobbs HH, Leitersdorf E, Leffert CC, Cryer DR, Brown MS, Goldstein JL. Evidence for a dominant gene that suppresses hypercholesterolemia in a family with defective low density lipoprotein receptors. J Clin Invest 1989: 84: 656-664

Hobbs HH, Russell DW, Brown MS, Goldstein JL. The LDL receptor locus in familial hypercholesterolemia: mutational analysis of a membrane protein. Annu Rev Genet 1990: 24 133-170.

Kozlowska A, Sadurska BB, Szymczyk T. Effect of dichlorvos on the activity of lipoprotein lipase from adipose tissue, on plasma lipids and postheparin lipolytic plasma activity in rats. Arch Toxicol 1988: 62: 227-229.

Lipid Research Clinics Program. Manual of laboratory operations, Vol. 1: Lipid and lipoprotein analysis. U.S. Dept. of Health, Education and Welfare. Publication no. 75-628 (NIH), Washington, D.C. US Government Printing Office 1974: 1-81.

Lipid Research Clinics Program Epidemiology Committee. Plasma lipid distribution in selected North American populations: the Lipid Research Clinics Program prevalence study. Circulation 1979: 60: 427-439.

Lussier-Cacan S, Bouthillier D, Davignon J. Apo E allele frequency in primary endogenous hypertriglyceridemia (Type IV) with and without hyperapobetalipoproteinemia. Arteriosclerosis 1985: 5: 639-643.

Ma Y, Bétard C, Roy M, Davignon J, Kessling AM. Identification of a second "French-Canadian" LDL receptor gene deletion and a rapid method to detect both deletions. Clin Genet 1989: 36: 219-228.

Miettinen TA, Aro A. Faecal fat, bile acid excretion, and body height in familial hypercholesterolemia and hyperglyceridaemia. Scand J Clin Lab Invest 1972: 30: 85-88.

Nora JJ, Lortscher RM, Spangler RD, Bilheimer DW. Familial hypercholesterolemia with "normal" cholesterol in obligate heterozygotes. Am J Med Genet 1985: 22: 585-591.

Reilly SL, Ferrell RE, Kottke BA, Kamboh MI, Sing CF. The gender-specific apolipoprotein $\mathrm{E}$ genotype influence on the distribution of lipids and apolipoproteins in the population of Rochester, MN. I. Pleiotropic effects on means and variances. Am J Hum Genet 1991: 49: 1155-1166.

Reilly SL, Ferrell RE, Sing CF. The gender-specific apolipoprotein $\mathrm{E}$ genotype influence on the distribution of plasma lipids and apolipoproteins in the population of Rochester, MN. III Correlations and covariances. Am J Hum Genet 1994: in press.

Reilly SL, Kottke BA, Sing CF. The effect of generation and gender on the joint distributions of lipid and apolipoprotein phenotypes in the population at large. J Clin Epidemiol 1990 43: 921-940.

SAS Institute Inc. SAS user's guide, version 6. SAS Institute Inc. 1989.

Sing CF, Haviland MB, Templeton AR, Zerba KE, Reilly SL. Biological complexity and strategies for finding DNA variations responsible for inter-individual variation in risk of a common chronic disease, coronary artery disease. Ann Med 1992: 24: 539-547.

Sing CF, Boerwinkle EA. Genetic architecture of inter-individual variability in apolipoprotein, lipoprotein and lipid phenotypes. In: Molecular approaches to human polygenic disease (Ciba Foundation Symposia 130). Wiley, Chichester, 1987: 99-127.

Sing CF, Davignon J. Genetics and molecular biology. Curr Opin Lipidol 1993: 4: 79-84.

Sing CF, Moll PP. Strategies for unravelling the genetic basis of coronary artery disease. In: Berg K, Retterstøl N, Refsum S, eds. From phenotype to gene in common disorders. Copenhagen: Munksgaard A/S International Press, 1990: 37-59.

Sing CF, Reilly SL. Genetics of common diseases that aggregate, but do not segregate, in families. In: Sing CF, Hanis CL eds. Genetics of cellular, individual, family and population variability. New York: Oxford University Press, 1993: 140161.

Sing CF, Zerba KE, Haviland MB. Genetic architecture of interindividual variation in plasma cholesterol. In: Bearn AG, ed. Genetics of coronary heart disease. Oslo: Institute of Medical Genetics, University of Oslo. 1992: 143-162.

Sing CF, Zerba KE, Reilly SL. Traversing the biological complexity in the hierarchy between genome and CAD endpoints in the population at large. Clin Genet 1994: in press.

Teng B, Sniderman AD, Soutar AK, Thompson GR. Metabolic basis of hyperapobetalipoproteinemia. Turnover of apolipoprotein B in low density lipoprotein and precursors and subfractions compared with normal and familial hypercholesterolemia. J Clin Invest 1986: 77: 663-672.

Thompson GR, Seed M, Niththyananthan S, McCarthy S, Thorogood $M$. Genotypic and phenotypic variation in familial hypercholesterolemia. Arteriosclerosis 1989: 9: 1-75-1-80.

Uauy R, Vega GL, Grundy SM. Coinheritance of two mild defects in low density lipoprotein receptor function produces severe hypercholesterolemia. J Clin Endocrinol Metab 1991: 72: 179-187.

Wilson PWF, Garrison RJ, Abbott RD, Castelli WP. Factors associated with lipoprotein cholesterol levels. Arteriosclerosis 1983: 3: 273-281.

Xhignesse M, Lussier-Cacan S, Sing CF, Kessling AM, Davignon J. Influences of common variants of apolipoprotein $\mathrm{E}$ on measures of lipid metabolism in a sample selected for health. Arterioscler Thromb 1991: 11: 1100-1110.

Zerba KE, Sing CF. The role of genome type-environment interaction and time in understanding the impact of genetic polymorphisms on lipid metabolism. Curr Opin Lipidol 1993: 4: 152-162. 